\title{
Barriers and Benefits of On-farm Quality Assurance System in Western Australia
}

\author{
A. Liu \\ Nanjing Agricultural University \\ P.J. Batt \\ China \\ Curtin University \\ Australia
}

Keywords: quality assurance system, on-farm, agriculture, farmer

\begin{abstract}
Food safety has become an important issue in the developed and developing countries. In order to meet consumers' increasing needs, many industries are adopting quality assurance systems in order to establish and protect a reputable brand. This paper seeks to identify the barriers and benefits influencing the implementation of on-farm quality assurance systems in Western Australia. For the 178 farmers who participated in the survey, most respondents believed that a quality assurance system would lead to better internal traceability, an improved awareness of food safety and reduce the risk of contamination. The main barriers towards the implementation of a quality assurance system were the increased amount of paperwork and the bureaucracy, the lack of any financial incentive, their ability to sell their grain without a quality assurance system, the lack of time, the high annual cost of certification, the high cost of implementation, and the belief that their customers did not require a quality assurance system.
\end{abstract}

\section{INTRODUCTION}

Western Australia offers the world a wide range of fresh, high quality food products including seafood, specialty meats, fruit and vegetables, flowers and honey. Western Australia's agrifood, fibre and fisheries production has increased in value by $30 \%$ from 1990/91 to 2007/08 to reach AUD \$13 billion (including value-added processed goods). This increase can be attributed to the application of new technologies and economies of scale. Food production in Western Australia represents approximately $14 \%$ of total Australian agrifood production. The agrifood sector contributes more than AUD $\$ 8$ billion to the Western Australian economy each year and creates employment for more than $9 \%$ of the State's workforce. With a relatively small domestic market of just over 2.1 million people, the State's agrifood industries are highly dependent on exports. Exports have continually undergone positive growth, rising from AUD \$2.3 billion in $1990 / 91$ to AUD $\$ 4.9$ billion in 2007/08. Agrifood is the State's second largest export sector after mining (DAFWA, 2009).

Maintaining Western Australia's global reputation as a supplier of safe, premium quality food is vital to retain market access, particularly in high value niche export markets. Several Western Australian Government agencies have implemented extensive campaigns to raise awareness and promote safe food practices among farmers, food processors, retailers and the food service sector (DAFWA, 2009). In recent years, many on-farm quality assurance systems have been developed and delivered to farmers, such as Better Farmer IQ, BEST Farms and SQF 1000. The aim of this research is to explore the farmers' awareness of quality assurance systems, and the barriers and benefits arising from the implementation of an on-farm quality assurance system. 


\section{QUALITY ASSURANCE SYSTEMS}

\section{Customer Drivers and Demands for Quality Assurance (QA) System}

Consumers in both the developing and developed countries demand high quality wholesome food products at reasonable prices. They also need to be protected from foodborne illness which may arise at any level of the supply chain (FAO, 2004). Consumers now consider quality to be the core measure of their total perception of the product or service delivered (Achilleas and Anastasios, 2008).

The emergence of the WTO has been instrumental in developing new approaches and requirements for the international trade in food. Import tariffs and quotas have been replaced by SPS barriers, which have provided new challenges and opportunities for all countries (Gregory and Orriss, 1999). Putting aside concerns about trade barriers, quality assurance systems have the potential to reduce many kinds of transaction costs by serving as the seller's guarantee of food safety and/or product quality, thereby increasing international competitiveness. Quality assurance systems can also improve operational efficiency by reducing product failure costs. Quality assurance systems directly affect a firm's costs, profits and market access, all of which may serve as an incentive for adopting a particular quality system. Some firms view quality assurance systems as a tool to improve operational efficiency because the systems both model and document the production process. These firms cite cost reduction as an important benefit they derive from certification. Other firms may seek quality assurance certification for the sole purpose of satisfying a customer's requirement (Holleran, Bredahl and Zaibet, 1999).

In the UK, incentives to adopt a quality assurance system were primarily related to crisis management and the restoration of consumer confidence following a number of high profile food safety scares. In Canada and Australia, the policy focus has been on risk management and the prevention of trade-threatening food safety issues (Hobbs, Fearne and Spriggs, 2002)

\section{Definition of Quality Assurance System}

The AS/NZS ISO 9000:2000 defines quality as the degree to which a set of inherent characteristics (physical, sensory, behavioural, temporal, ergonomic and functional) fulfil requirements, needs or expectations that were stated, generally implied or obligatory (Standards Australia/Standards New Zealand, 2000). The concept of food quality is determined by the sensory attributes, chemical composition, physical properties, and level of microbiological and toxicological contaminants, shelf-life, packaging and labelling. The consumer is the key in defining quality because they not only demand a high level of food safety, but also have concerns about environmental sustainability, the use of natural resources and the protection of farmers' and animal welfare (Achilleas and Anastasios, 2008). Environmental and welfare values, often described as credence or intrinsic quality values, are becoming increasingly aligned with a greater suspicion of industrial food processes and the desire to support sustainable farming practices. Consumers are becoming more interested in the non-price attributes of food and increasingly aware of such issues as conservation, water pollution, salinity and soil degradation (Batt, Noonan and Kenyon, 2006).

Quality assurance can be defined as controlling the process of production to produce a product free of defects (Green, 1993). Instead of relying on inspection to assure product quality, inspection is focused on providing feedback so the process can be refined and improved, thereby improving product quality. Quality assurance is a management system which controls each stage of food production from procurement of raw materials, 
harvesting, processing and final consumption (Fellows, Axtell and Dillon, 1995). According to the European Organization for Quality Control (cited by Lásztity and Salgó, 2002), quality assurance is a system of activities whose purpose is to provide evidence that the quality control task has been done effectively. Another definition, which is more clear for the consumer, is that quality assurance includes all those planned and systematic actions necessary to provide adequate confidence that a product or service will satisfy given requirements (Lásztity and Salgó, 2002). Quality assurance includes a series of systematic actions that are strongly connected with standards and quality control methods, including breeding, growing, prestorage manipulation, storage, transport and, in a wider sense, the processing and distribution of food products.

\section{Benefits of Adopting a Quality Assurance System}

As farmers are economically rational, they work on their farm not only to meet their anticipated household needs, but also to achieve greater economic benefits. If quality assurance systems are to be accepted by farmers, there must be a tangible benefit.

Quality assurance systems help to improve food safety and reduce risks. There are many different types of contaminants that can affect the quality of grains and their end products. Contaminants can be bacterial, chemical or physical. An example of bacterial contamination could be salmonella from rodent droppings in the grain. Chemical contamination is one of the more serious issues today as many countries, including Japan, have imposed limits on the levels of contamination that are allowable in their grain imports. Physical contamination comes from finding foreign material in the grain such as weed seeds, metal and other types of grain (Robey and Brouwer, 1998).

Producing grains that are free from or contain minimal amounts of contaminants is very important to the Australia food industry. Small amounts of contaminated grain in a large amount of delivered grain may not be seen as harmful, but in the long run, this can have a significant detrimental impact on grower payments and the reputation of the WA industry (CBH, 2004). Quality assurance systems have been adopted to avoid food borne illness, injury and spoilage, and to reduce the risk of contamination (Orriss, 1999).

Quality assurance systems will reduce the cost overall. As farms increase in size, the cost of implementation and managing a quality assurance system decreases. Thus, producers operating larger farms are more likely to profit from adopting the quality assurance system. With a quality assurance system in place, prevention costs and appraisal costs may rise, but failure costs will be greatly reduced. As total costs on the farm are reduced, profitability should increase (Robey and Brouwer, 2000). Karaka, Alexander and Maier (2007) show that under a quality assurance system, reduced cost may come in the form of fewer penalties due to the production of better quality grain. In WA, quality assured farmers receive a premium of AUD $\$ 0.50$ per tonne. However, from $2010 / 11$, those farmers who are not quality assured will pay a penalty of AUD $\$ 2.50$ per tonne to have their grain tested for chemical residues.

Quality assurance systems will also improve relationships with suppliers and customers and greatly facilitate market access. Relationships built around trust, confidence and reliability provide more confidence in the supply chain, which leads to increased sales and market share. Having a quality assurance system in place may also open up new markets that demand process verification and traceability protocols (Karaca, Alexander and Maier, 2007). A quality assurance system can also be used as a marketing tool that protects companies in an environment of distrust and as a differentiating strategy 
that adds value to their products and justifies higher prices for their products in the market (Achilleas and Anastasios, 2008).

\section{Barriers of Adopting a Quality Assurance System}

To adopt a quality assurance system, small enterprises need to know that performance improvements are guaranteed, as they are seldom willing to invest in systems that promise only potential returns (Karipidis et al., 2009).

In small and medium sized enterprises, the lack of human resources impacts upon management practices, as time constraints and the high costs of training impinge upon the normal operation of the business (Van der Spiegel, Luning and Jongen, 2003).

The large amounts of extra paperwork have also been found to be a discouraging factor. Quality assurance programs are often very formal and inflexible and there is much specialized knowledge that accompanies each individual enterprise. Business managers may not know what documents are required and how the data is to be recorded. If a small business does not have a quality manager, they may need to hire an external consultant at considerable cost (Karipidis et al., 2009).

Lack of time is also related to the amount of new information that a farmer has to learn to adopt a quality assurance system. Depending on the system, farmers may have to learn new ways of doing things. This may include learning about new cropping systems, new inputs and revising existing cropping practices (Vancaly, 1992).

One of the barriers to the more widespread adoption of quality assurance systems is that they are not required by all customers. Food that is quality assured is often more expensive than food which is not and factors like socio-demographic characteristics, perceived quality and risks, can affect whether the customer is willing to pay a premium. An awareness of animal welfare and health risks associated with the use of pesticides rise as consumers' disposable income increases. If some customers do not require food that meets certain prescribed standards, farmers see no point in quality assuring their produce (Achilleas and Anastasios, 2008).

\section{METHODOLOGY}

A questionnaire was developed after a comprehensive literature review and discussion with industry experts. The first part of the questionnaire included a number of warm-up questions about the location of the farm, the size of the farm, the amount of land that was cropped, the farming system, the area of each crop cultivated (hectares) and the average yields for each crop ( $t / h a)$. At the end of this section, respondents were asked to answer different parts of the questionnaire contingent upon the level of quality assurance their farming enterprise had achieved.

In Part Two, respondents who had a quality assurance system were asked to indicate the extent to which they believed that an on-farm quality assurance system had impacted on their farm business. Respondents were asked what assurance system they had, how many years they had been working under this system, and why they preferred to operate under this system. In Part Three, respondents were who were in the process of implementing a quality assurance system on-farm were asked about the perceived benefits of having a quality assurance system, which system they were planning to implement and why. In Part Four, respondents who had no intention of implementing a quality assurance system or who had once had an on-farm quality assurance system but had since abandoned it, were asked to indicate why they had chosen not to implement or to abandon an existing quality assurance system. 
In Part Five, all respondents were asked to indicate who they believed were the most important drivers for quality assurance on-farm. Respondents were then asked to indicate the extent to which they were supportive of on-farm quality assurance systems. Part Six sought to obtain some demographic information.

The questionnaire was pre-tested and then despatched to potential respondents by under graduate students, either by personal invitation or by mail. In order to improve the response rate, follow-up calls were also made to remind potential respondents. A total of 700 questionnaires were sent out during March-April, 2009.

The data preparation process included questionnaire checking, editing, coding, transcribing, adjusting the data and selecting a data analysis strategy. Coding the unstructured questions meant assigning each of the respondent's comments with a numerical code. This allowed for these questions to be statistically analysed.

The data was loaded in SPSS 17.0 for analysis.

\section{RESULTS \\ Respondents}

Due to many constraints, only 178 farmers responded to the survey instrument, a response rate of $25 \%$. Not unexpectedly, the majority of the respondents were male $(91 \%)$. The largest age group were respondents aged 45-54 years (38\%), followed by respondents aged 35-44 years (23\%), and respondents aged 55-64 years (18\%). Respondents' farms were located in 47 different shires across the WA wheat belt. The survey results suggested that the average farm size was 4,060 ha. However, as the standard deviation was greater than the mean, this suggested that the sample size was too small to provide an accurate estimate of the mean.

The survey results indicated that most respondents had been farming for an average of 26 years, with almost $60 \%$ of the respondents indicating that they were likely to continue farming beyond the next decade. The majority of respondents (78\%) had completed at least 5 years of secondary school (Year 12). Some 30\% had attended university, with $22 \%$ having completed an undergraduate degree and $8 \%$ having completed a post-graduate degree. Some $37 \%$ of the respondents had some formal training in agriculture.

\section{Quality Assurance}

Among the 178 farmers surveyed, one half had a quality assurance system in place. A smaller number of the respondents $(10 \%)$ were in a process of introducing a quality assurance system. However, some $40 \%$ of the respondents did not have a quality assurance system in place.

The general consensus among grain farmers was that bulk handlers were the most influential actor encouraging them to implement a quality assurance system on-farm (5.09). Other actors in terms of importance were food processors (4.59), exporters (4.34), customers (4.06), retailers (3.99) and government (3.50), while other producers (2.46) and suppliers (2.13) were less influential.

The majority of respondents $(87 \%)$ indicated that they had not had any grain rejected last season. For those that had grain rejected, the main reasons for rejection were stones and soil (38\%), sticks (13\%) and live insects (13\%). The quantity of grain rejected ranged from $8 \mathrm{t}$ to $700 \mathrm{t}$. It was of interest to find that the presence or absence of a quality assurance system had no impact on the amount of grain rejected: some $11.6 \%$ of those respondents who had a quality assurance system, some $12.5 \%$ of those respondents who 
were in the process of implementing a quality assurance system, and $14.9 \%$ of those who did not have a quality assurance system on-farm, had some grain rejected last season.

\section{Benefits of Adopting a Quality Assurance System}

For those respondents who already had a quality assurance system in place or were currently in the process of introducing a system, most believed that the quality assurance system would provide better farm records (4.49). The adoption of quality assurance was perceived to lead to better internal traceability (4.25), an improved awareness of food safety (4.13) and to reduce the risk of contamination (4.00). There was a moderate belief that a quality assurance system would improve access to information about industry risks (3.57), that customers needs would be better met (3.48), improved occupational health and safety (3.42), enhanced competitiveness in the market (3.41), improved relationships with customers (3.35), an ability to run the farm better (3.16), to have better control of the farm production system (3.05), and improved relationships with suppliers (3.05)(Table 1). However, some $65 \%$ of the respondents, who had a quality assurance system or were in a process of implementing a quality assurance system, highlighted that there were few additional benefits.

\section{Barriers to Adopting a Quality Assurance System}

For those respondents who did not have an on-farm quality assurance system in place, the most frequently cited reason for not introducing a quality assurance system was the absence of any financial benefits (41\%). The large amount of paper work (22\%), time constraints $(15 \%)$, customers did not need it (13\%), the small size of the business $(12 \%)$, too much bureaucracy $(10 \%)$, and the high cost $(10 \%)$ were additional reasons given why grain farmers chose not to introduce a formal quality assurance system.

In responding to a number of fixed response statements, those respondents who did not have a quality assurance system on their farm rated the increased amount of paperwork and the bureaucracy as the major impediments (5.22)(Table 2). The second most important reason why respondents had chosen not to adopt a quality assurance system was the lack of financial incentives (4.91). Other reasons given were that they could sell all their grain now without a quality assurance system (4.69), the lack of time (4.51), the high annual cost of certification (4.49), the high cost of implementation (4.18), and their customers did not require a quality assurance system (4.07).

Only two respondents said that they had abandoned a quality assurance system. Their reasons were that quality assurance was common sense; it made no difference to product quality and there were no market incentives to adopt a quality assurance system.

\section{Differences between Farmers}

A significant difference was found between the farm size and quality assurance system status on-farm. The average farm size for respondents who had a quality assurance system was 5,031 ha, whereas the average farm size for respondents who were in the process of implementing a quality assurance system was 3.472 ha. The average farm size for those farmers who did not have a quality assurance system was 2,997 ha.

There was also a significant difference between quality assured status and the farmers' awareness of food safety risks. Some $94 \%$ of those respondents who had an onfarm quality assurance system had regularly heard about food safety risks, while $75 \%$ of respondents who did not have a quality assurance system had heard very little about food safety risks. Not unexpectedly, those respondents who had a quality assurance system in 
place were more supportive of the need to introduce an industry-wide quality assurance system. Conversely, those farmers who had not implemented a quality assurance system were more likely to oppose or reject the introduction of a generic on-farm quality assurance system.

\section{DISCUSSION AND CONCLUSION}

As Orriss (1999), Achilleas and Anastasios (2008), Karaca, Alexander and Mair (2007) suggested, WA grain farmers believed that an on-farm quality assurance system would provide better farm records, lead to better internal traceability, an improved awareness of food safety and reduce the risk of contamination. However, few farmers believe that a quality assurance system will lead to lower costs or improved returns.

As the has literature suggested, the lack of any financial incentive, the increased amount of paper work and the added bureaucracy were the major barriers to the adoption of a quality assurance system. Farmers had abandoned an on-farm quality assurance system because they thought that it made no difference to quality and there were no market signals to the contrary.

\section{Literature cited:}

Achilleas, K and Anastasions, S. 2008. Marketing aspects of quality assurance systems, British Food Journal.110: 829-839.

Australian Oilseeds Federation. 2004. Quality Assurance (QA) in Oilseeds. Fast facts Quality Assurance, 1-4.

http://www.australianoilseeds.com/data/assets/pdf_file/0019/946/FastFacts4-Quality Assurance.pdf

Batt, P.J., Noonan, J.D. and Kenyon, P. 2006. Global trends analysis of food safety and quality systems for the Australian food industry. DAFF. Canberra.

CBH. 2004. Better QA for CBH growers. http://www.cbh.com.au/ index.html.

DAFWA. 2009. Western Australia's Agrifood, Fibre \& Fisheries Industries 09.

FAO. Food engineering, quality and competitiveness in small food industry systems with emphasis on Latin America and the Caribbean. FAO Agricultural Services Bulletin 156. http://www. cababstractsplus.org/ab stracts/Abstract.aspx?AcNo=20053092776

Fellows, P., Axtell, B. and Dillon, M. 1995. Quality assurance for small-scale rural food industries. FAO Agricultural Services Bulletin No.117.

http://www.fao.org/docrep/V5380E/V5380E04.htm\#Glossary.

Green, A.1993. Applying quality assurance principles to good control. Food Control 4:2-6

Henzell, T. 2007. Australian agriculture: Its history and challenges, CSIRO publishing, Australia

Hobbs, J.E., Fearne, A. and Spriggs, J. 2002. Incentive structures for food safety and quality assurance: an international comparison. Food Control 13:77-81.

Holleran, E., Bredahl, M.E. and Zaibet, L. 1999. Private incentives for adopting food safety and quality assurance. Food Policy 39:669-683.

Karaca, U. Alexander, C. and Maier, D. 2007. Does on-farm quality assurance pays? A cost benefits analysis of the Grainsafe system. Journal of Agricultural and Applied Economics 39:541-556.

Karipidis, P., Athnassiadis, K., Aggelopoulos, S. and Giompliakis, E. 2009. Factors affecting the adoption of quality assurance systems in small food enterprises. Food Control 20: 93-98. 
Küepper, G. and Batt, P.J. 2009. Enhancing the international competitiveness of the Western Australia food and beverage industry through facilitating the adoption of quality assurance (QA) programs. Proceedings IAMA World Congress. Budapest. http://www.ifama.org/library.asp?collection=2009_budapest\&volume=symposium/10 21_paper.pdf

Lásztity, R. and Salgó, A. 2002. Quality assurance of cereals - past, present, future. Periodica Polytechnica - Chemical Engineering 46: 5-13.

Orriss, G.D. 1999. Equivalence of food quality assurance systems. Food Control 10: 255260.

Robey, D.P. and Brouwer, J.B. 2000. Increased market share for Australian pulses: A quality assurance strategy.

http://www. csu.edu.au /special/ agronomy/papers/264/264.html

Standards Australia/Standards New Zealand. 2000. Quality management systems. Fundamentals and vocabulary.

http:// www. leader products .com.au/10_Accreditation/images/ISO_9000.pdf

Van der Spiegel, M., Luning, P.A., Ziggers, G.W. and Jongen, W.M.F. 2003. Towards a conceptual model to measure effectiveness of food quality systems. Trend in Food Science and Technology 14: 423-431.

Vanclay, F. 1992, Barriers to adoption: a general overview of the issues. Rural Society 2: 47-53. 
Table 1: Benefits for Farmers to Have a Quality Assurance System

\begin{tabular}{lcr}
\hline Factors & Mean & $\begin{array}{r}\text { Standard } \\
\text { Deviation }\end{array}$ \\
\hline Provide better farm records & 4.49 & 1.37 \\
Provide better internal traceability & 4.25 & 1.33 \\
Improve awareness of food safety & 4.13 & 1.53 \\
Reduce risk of contamination & 4.00 & 1.53 \\
Improve access to information on industry risks & 3.57 & 1.41 \\
Allow me to better meet customers needs & 3.56 & 1.47 \\
Improve my on-farm environmental credentials & 3.48 & 1.59 \\
Improved occupational health and safety on-farm & 3.42 & 1.47 \\
Enhanced competitiveness in export markets & 3.41 & 1.49 \\
Improved relationships with customers & 3.35 & 1.42 \\
Enabled me to run my farm better & 3.16 & 1.40 \\
Given me better control over my production system & 3.05 & 1.36 \\
Improved relationships with suppliers & 3.05 & 1.48 \\
Improve market access & 2.95 & 1.48 \\
Led to fewer crop establishment mistakes & 2.95 & 1.59 \\
Improve returns & 2.39 & 1.34 \\
Reduce cost & 2.07 & 1.20 \\
\hline
\end{tabular}

Where 1 is "not at all important" and 6 is "very important" 
Table 2: Barriers for Farmers not to have a Quality Assurance System

\begin{tabular}{lcc}
\hline & Mean & Std. Deviation \\
\hline Increased paperwork /bureaucracy & 5.22 & 1.21 \\
Lack of financial Incentive & 4.91 & 1.43 \\
I can sell all my grain now & 4.69 & 1.43 \\
Lack of time & 4.51 & 1.42 \\
High annual cost of certification & 4.49 & 1.44 \\
High cost of implementation & 4.18 & 1.62 \\
Customers do not require it & 4.07 & 1.51 \\
Small size of the business & 3.41 & 1.81 \\
Conflict Information & 3.41 & 1.70 \\
Lack of information and knowledge & 3.19 & 1.61 \\
Organization resistance & 3.16 & 1.68 \\
Food safety is not a statutory requirement & 2.97 & 1.64 \\
Lack of consultant/ quality trainers & 2.76 & 1.54 \\
\hline
\end{tabular}

Where 1 is "not at all important" and 6 is "very important" 